\title{
Validation of satellite-based soil moisture retrievals from SMAP with in situ observation in the Simineh-Zarrineh (Bokan) Catchment, NW of Iran
}

Khaled Haji Maleki a*, Ali Reza Vaezi a, Fereydoon Sarmadian b, Wade T. Crow c

\author{
a Department of Soil Science, Faculty of Agriculture, University of Zanjan, Zanjan, Iran \\ b Department of Soil Science, Faculty of Agriculture, University of Tehran, Karaj, Iran \\ c USDA-ARS Hydrology and Remote Sensing Lab, Beltsville, MD, USA
}

\begin{abstract}
Soil moisture is an influential parameter in land surface hydrology and precise soil moisture data that can help researcher to realize the climate changes and land-atmosphere interactions. A initial struggle for the utilize of soil moisture data from satellite sensors is their reliability. It is important to appraise the dependability of those data before they can be regularly used at a global or local scale. In this study, the satellite soil moisture data was evaluated from the Soil Moisture Active/Passive (SMAP) over Simineh-Zarrineh Catchment in Bokan region, NW of Iran. A total of 287 soil samples as ground-based observations in the time period of 03 April to 03 December 2017 were taken for SMAP data validation. Results showed that the satellite data and in situ observation has a good correlation, with a mean correlation (r) value of 0.63 in total. This correlation level showed that, commonly, the SMAP soil moisture products over Simineh-Zarrineh Catchment (Bokan) have great quality, and it would be valuable for versatile utilization, including monitoring of land surface, weather prediction, modeling of hydrological process, soil loess monitoring, and climate studies. The results reveal that the remotely sensed data demonstrate the good correlation with in situ observation across the dry land with mean correlation (r) values of 0.67 throughout the time period. Particularly, SMAP soil moisture reveal a constant structure for obtain the spatial distribution of surface soil moisture. Additional researches are necessary for well realizing the SMAP data.

Keywords: Dry land, NDVI, RMSE, Soil water.
\end{abstract}

(C) 2019 Federation of Eurasian Soil Science Societies. All rights reserved

\section{Introduction}

Soil moisture is a main control on many hydrological phenomena, particularly runoff formation, evaporation of soil and transpiration of plant. Soil moisture is one of the most difficult variables to prospect, because of its interaction with parameters as an example soil types, topography and vegetation (Wilson et al., 2004). The utilize satellite data has become a potent tool to increase our knowledge of the impress of soil moisture in the hydrological phenomena in some regions, e.g., land-atmosphere phenomena (Miralles et al., 2012; Taylor et al., 2012); weather and runoff prediction (Brocca et al., 2010; Bisselink et al., 2011); landslides (Brocca et al., 2012); agricultural drought monitoring (Sánchez et al., 2018) and precipitation products (Chen et al., 2012).

In the last two decades, several researches have illustrated that soil moisture can be recaptured by satellite missions, the most important ones are the Soil Moisture Ocean Salinity (SMOS) (Kerr et al., 2010) and Soil Moisture Active/Passive (SMAP) (Entekhabi et al., 2014). Lately, NASA's Soil Moisture Active/Passive (SMAP) satellite mission was inaugurated on January 31, 2015. The goal of the operation is monitoring of

\footnotetext{
${ }^{*}$ Corresponding author.

Department of Soil Science, Faculty of Agriculture, University of Zanjan, Zanjan, Iran

Tel.: +989194017683 e-ISSN: 2147-4249
}

E-mail address: khaled.hajimaleki@yahoo.com DOI: $10.18393 /$ ejss.608005 
soil moisture and landscape freeze/thaw state at global scale. The SMAP measurements will, therefore, donate to enhanced predictions of water, energy and carbon movement between the land and atmosphere (Entekhabi et al., 2010). Nevertheless, as an outcome of the several procedures used for various satellite data, the quality and continuity of passive microwave soil moisture data changes in spatially and temporally (Owe et al., 2001; Parinussa et al., 2011; Dorigo et al., 2016). The appraisal of remotely sensed data is essential to guide their accurate apply and to enhance our comprehension of their advantages and disadvantages under various situation over the world and at various times.

In the circumstance of the SMAP mission, the requirement is an accuracy of $0.04 \mathrm{~cm}^{3} . \mathrm{cm}^{-3}$ for volumetric soil moisture (Entekhabi et al., 2014). Moreover mission demands standard, validation prepares the users with quality confidence, which in theory should comprise higher assurance and acceptation, resulting in further to extensive utilize of the mission products. This in turn prepares encourage for the mission and its substitutes. Eventually, from the scientific viewpoint remote sensing in special, there will be approximately uncertainty in the data because of lack of clarity in defining contributing area and depth for the different satellite operation sensors and frequencies. Validations help us to find a solution for these subjects and enhance algorithms through a careful appraisal of algorithm efficiency and anomalies.

Some researchers have appraised soil moisture data based on passive microwave sensors versus in situ observation across various areas (Brocca et al., 2011; Albergel et al., 2012; Parinussa et al., 2015; Wu et al., 2016). Former studies have also concentrated on the comparison of some soil moisture data (Kerr et al., 2012; Albergel et al., 2012; Dorigoet al., 2015). Leroux et al. (2014) performed comparisons between the SMOS, ASCAT, and ECMWF (European Centre for Medium-Range Weather Forecasts) soil moisture data and the outcomes show that SMOS retrievals are adjacent to the ground measurements with a low average root mean square error of $0.061 \mathrm{~cm}^{3} . \mathrm{cm}^{-3}$. Al-Yaari et al. (2014) conducted a comparison among the SMOS and AMSR-E data used by extended period of time and shown that in terms of correlation values, the SMOS data was discovered to better capture the soil moisture temporal dynamics in generously vegetated biomes while good outcomes for AMSR-E were obtained over arid and semi-arid biomes. Zeng et al. (2015) analyzed comparison the AMSRE, AMSR2 and ASCAT data applying annual and seasonal succession, and the outcomes show that the AMSR-E and AMSR2 data were underestimated generally. Zeng et al. (2016) performed a introductory assessment of the SMAP radiometer data versus in situ observations gathered from various networks that contain disparate climatic and land surface situations, and the outcomes demonstrate that the SMAP data is in excellent concurrence with the in situ observations, despite the fact that it show dry or wet bias at various areas.

Because of the lack of long time period SMAP soil moisture; there is an absence of sufficient investigation compared to other soil moisture data. The SMAP data has been appraised in comparison with the uncertainty of downscaled brightness temperature obtained from airborne and ground remarks concurrently (Leroux et al., 2014; Das et al., 2016).

Due to the lack of systematic ground based monitoring of soil moisture and irregular topographies in the region such as studies would be essential and should be done. SMAP data can be used to understanding hydrological processes in the region because of good temporal resolution. In this research, it would be efforts to comparison SMAP data at daily time scales over the Simineh-Zarrineh catchment in Bokan city, NW of IRAN used by in situ observation from soil samples for 03 April to 03 December 2017. It would be the evaluation of SMAP data by ground based soil moisture in various land uses of semi-arid region to achieve the overall outlook of the SMAP soil moisture data accuracy and prepare a more practical outline for the applicability and accuracy of SMAP for various implementation.

\section{Material and Methods}

\section{Study area}

The Simineh-Zarrineh catchment with an area of $17563 \mathrm{~km}^{2}$ is placed in the mountainous area of northwest of Iran and covered West Azarbaijan, East Azarbaijan and Kurdistan provinces with 56, 16 and 28 percentage of the catchment area respectively. (Urmia Lake Restoration National Committee, 2015). The Simineh-Zarrineh catchment is located (latitude $35^{\circ} 42^{\prime} 14^{\prime \prime}$ to $37^{0} 44^{\prime} 31^{\prime \prime} \mathrm{N}$, longitude $45^{0} 31^{\prime} 32^{\prime \prime}$ to $47^{\circ} 22^{\prime} 21^{\prime \prime} \mathrm{E}$ ) in the southern and southeastern parts of Urmia Lake and regarding the size it is the largest sub-basin of Urmia Lake basin (Figure 1). The lowest and highest elevation above sea level in the area is 1254 and 3389 meter respectively. Dominant crop in dry lands are barely, wheat and in irrigated agricultural land are sugar beet, alfalfa and apple. 


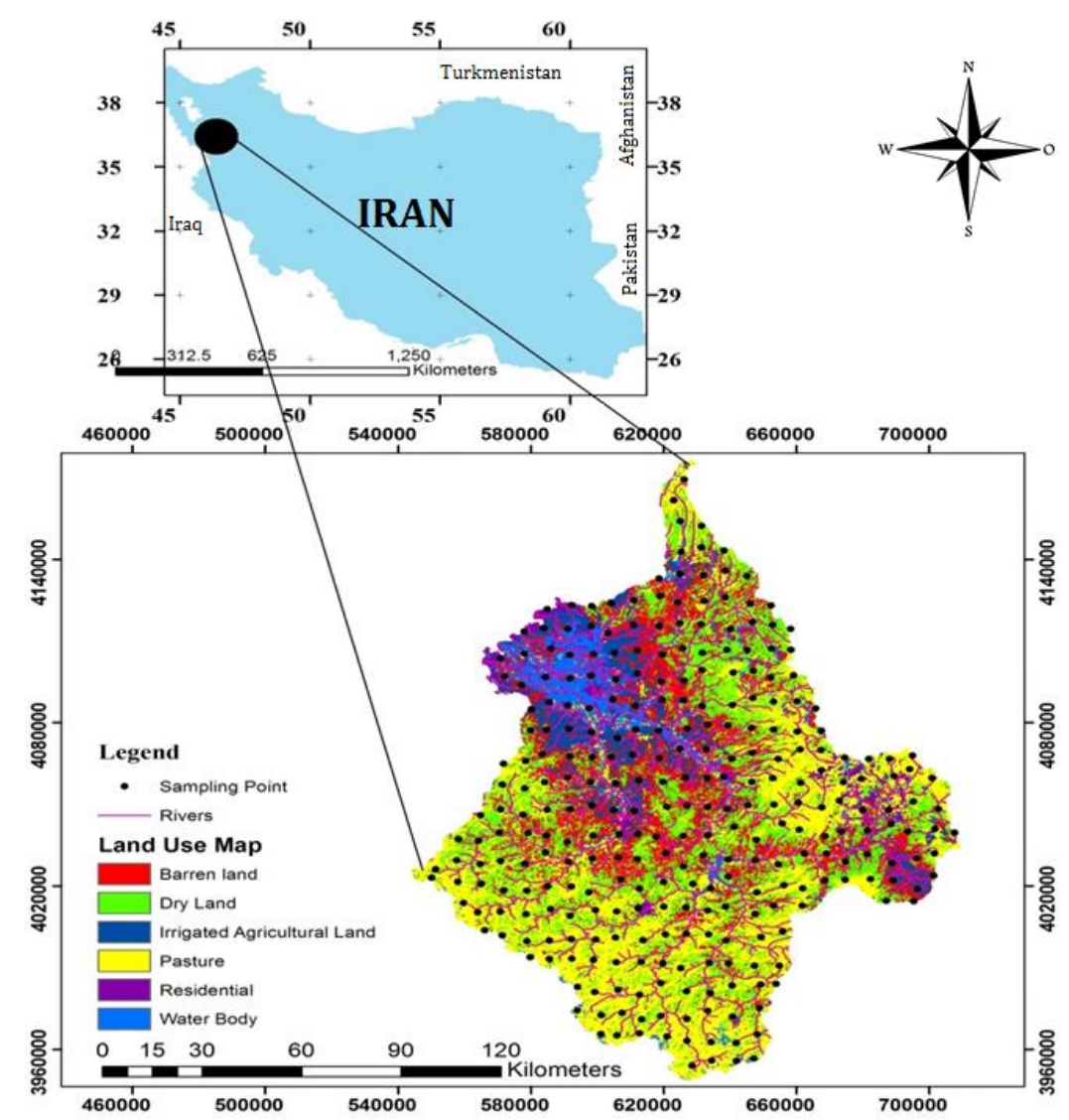

Figure 1. The 2018 Land Use Map of Simineh_Zarrineh Catchment (Bokan), in-situ soil moisture observations sites and rivers.

The rivers of Zarrinehrud and Siminehrud are perennial streams in this catchment with a highest discharge of about 3 billion cubic meters annually in the period 1995-2014 are regarded as water full rivers in the country. Zarrinehrud and Siminehrud river basins supply about $52 \%$ of environmental flow of Urmia Lake in each year. The length of Zarrinehrud and Siminehrud river is about 240 and $200 \mathrm{~km}$ and the area of the basin is 11642 and $5921 \mathrm{~km}^{2}$ respectively. (Ahmadaali et al., 2018). The local climate is characterized by a dry steppe, hot summers, cold winters, low precipitation, high evaporation and low humidity. The annual average temperature and annual average precipitation are $12.1 \mathrm{C}^{0}$ and $423 \mathrm{~mm}$ respectively.

\section{Datasets}

SMAP satellite was launched on January 2015 by the National Aeronautics and Space Administration (NASA) (Entekhabi et al., 2010). SMAP supplies soil moisture data that envelopment the upside $5 \mathrm{~cm}$ of the soil column with an preciseness of $0.04 \mathrm{~cm}^{3} . \mathrm{cm}^{-3}$ and a spatial resolution of 3, 9, $36 \mathrm{~km}$, and envelopments the earth every three days (Entekhabi et al., 2010; Leroux et al., 2016; Das et al., 2011; Reichle et al., 2016). The SMAP criterion science data are demonstrated in the Table 1. on the whole, the SMAP task will create 15 distributable data representing four levels of data processing.

Table 1. Product Information of SMAP Mission

\begin{tabular}{llll}
\hline No. & Product & Description & Resolution \\
\hline 1 & L1A_Radiometer & Radiometer Data in Time-Order & - \\
2 & L1A_radar & Radar Data in Time-Order & - \\
3 & L1_TB & Radiometer T B in Time-Order & $(36 \times 47 \mathrm{~km})$ \\
4 & L1B_S0_LoRes & Low-Resolution Radar 6, in Time-Order & $(5 \times 30 \mathrm{~km})$ \\
5 & L1C_S0_HiRes & High-Resolution Radar 6. in Half_Orbit & $1 \mathrm{~km}(1-3 \mathrm{~km})$ \\
6 & L1C_TB & Radiometer T B in Half-Orbit & $36 \mathrm{~km}$ \\
7 & L2_SM_A & Soil Moisture(Radar) & $3 \mathrm{~km}$ \\
8 & L2_SM_P & Soil Moisture(Radiometer) & $36 \mathrm{~km}$ \\
9 & L2_SM_AP & Soil Moisture(Radar+Radiometer) & $9 \mathrm{~km}$ \\
10 & L3_FT_A & Freeze/Thaw State(Radar) & $3 \mathrm{~km}$ \\
11 & L3_SM_A & Soil Moisture (Radar) & $3 \mathrm{~km}$ \\
12 & L3_SM_P & Soil Moisture (Radiometer) & $36 \mathrm{~km}$ \\
13 & L3_SM_AP & Soil Moisture (Radar+Radiometer) & $9 \mathrm{~km}$ \\
14 & L4_SM & Soil Moisture (Surface and Root Zone) & $9 \mathrm{~km}$ \\
15 & L4_C & Carbon Net Ecosystem Exchange (NEE) & $9 \mathrm{~km}$ \\
\hline
\end{tabular}


Level 1 product contains instrument-related data and appears in granules that are based on half orbits of the SMAP satellite. Level 2 products are geophysical retrievals of soil moisture on a fixed Earth grid based on Level 1 products and ancillary information; the Level 2 products are output on a half-orbit basis. Level 3 products are daily composites of Level 2 surface soil moisture and freeze/thaw state data. These level products are daily global composites of the Level 2 geophysical retrievals for an entire UTC (Coordinated Universal Time) day. Level 4 products are model-derived value-added data products of surface and root zone soil moisture and carbon net ecosystem exchange that support key SMAP applications and more directly address the driving science questions. These level products contain output from geophysical models utilizing SMAP data (https://smap.jpl.nasa.gov/data/). In addition, the SMAP soil moisture data supplies measurements and analysis update data including pertinent geophysical fields reported as 3-hourly time averages, allocated over a 9-km grid (Reichle et al., 2015). In this research Level 4 products was used for validation and verification. All of SMAP data is downloadable from https://nsidc.org

\section{In Situ Soil Moisture and Land Use Data}

Sampling strategy based on regular sampling grid and in accordance with the pixel size of the satellite. In situ soil moisture samples in depth of 0 to $5 \mathrm{~cm}$ were collected from 287 soil sample points at six time periods in this paper (Figure 1). It has been attempt to select number of point based on the percentage of area covered by each land uses (Table 2). At each monitoring point, soil samples of topsoil $(0-5 \mathrm{~cm})$ were collected using a core sampler with $5-\mathrm{cm}$ diameter and $12 \mathrm{~cm}$ height on six occasions from 03 April to 03 December 2017. Soil samples were taken in accordance with satellite data acquisition time. But when the surface was covered with snow, sampling was not done. The minimum and maximum intervals of soil samples point were 10.7 and $7.2 \mathrm{~km}$ respectively. After collecting, samples were put in plastic bag with tight fitting lids. Soil moisture was measured using mass method by the oven in the lab. After weighing, samples for 24 to 48 hours were dried in an oven at $105^{\circ} \mathrm{C}$ and then volumetric soil moisture percentage had been determined.

Data acquired in time period of 03 April to 03 December 2017. The soil moisture observation points acquired data for six days according to time table of SMAP mission. During the sampling process it has also been tried to the spatial distribution of the samples are located in all land uses.

The land use map is classified in accord with the 2018 Landsat 8 satellite data with a spatial resolution of 30 $m$ in July (Figure 1). It was utilized to analyze the efficiency of SMAP data for various land use types over the Simineh-Zarrineh catchment (Bokan). The Land use map 2018 covering soil samples and rivers location is displayed in Figure 1. The number of soil samples distributed in various spatial areas and land use types is displayed in Table 2 . Total of 287 soil samples were chosen for daily analysis.

Table 2. The number of soil sample sites situated in various land use over the Simineh_Zarrineh Catchment (Bokan).

\begin{tabular}{lcc}
\hline Land Use & Percentage of Area(\%) & Number of Soil Samples \\
\hline Water body & 4.65 & 0 \\
Pasture & 35.65 & 106 \\
Irrigated agricultural land & 8.43 & 41 \\
Barren land & 19.56 & 57 \\
Dry land & 28.22 & 83 \\
Residential land & 3.51 & 0 \\
\hline
\end{tabular}

\section{Methods}

Previous researches have follow various approaches to compare remotely sensed soil moisture with in situ measurements (Entekhabi et al., 2010; Wu et al., 2016; Crow et al., 2012; Wang et al., 2016). In this study, the qualities of SMAP data were appraised by comparing them to the in situ soil moisture measurement from ground points. Four statistical indicators were used, containing the mean difference (MD), the root mean square difference (RMSD), the unbiased root mean square error (ubRMSE) and the correlation coefficient (R).

The accuracy of SMAP data are assessed regarding the MD, the RMSD, and the R. The MD represents the bias, namely the systematic difference between satellite soil moisture retrievals and in situ soil moisture observation. The MD was determined by the following equation (1):

$$
M D=\frac{\sum_{i=1}^{n}\left(Q_{S}(i)-Q_{m}(i)\right)}{N}
$$

The RMSD is a frequently used measure of the differences between SMAP data and in situ observation. RMSD is the square root of the average of squared errors. The RMSD was expressed by following equation (2): 


$$
R M S D=\sqrt{\frac{\sum_{i=1}^{N}\left(Q_{s}(i)-Q_{m}(i)\right)^{2}}{N}}
$$

Where; $Q_{s}$ represents as a remotely sensed soil moisture $\left(\mathrm{cm}^{3} \cdot \mathrm{cm}^{-3}\right), Q_{m}$ is the in situ soil moisture observation $\left(\mathrm{cm}^{3} \cdot \mathrm{cm}^{-3}\right)$ and $\mathrm{N}$ expressed by total number of samples, and i represents a specific sample.

So that get an enhanced authentic prediction of RMSD, the bias can be absolutely eliminate by determining the ubRMSE that illustrates random error. The ubRMSE is computed by the following equation (3) (Entekhabi et al., 2014).

$$
\text { ubRMSE }=\sqrt{(R M S D)^{2}-(M D)^{2}}
$$

The $r$ reveal the proportionate of preciseness among SMAP data and in situ soil moisture observation. The correlation coefficient(r) expressed by following equation (4):

$$
r=\frac{\sum_{i=1}^{n}\left(\theta_{s}(i)-\mu_{s}\right)\left(\theta_{m}(i)-\mu_{m}\right)}{(N-1) \sigma_{s} \sigma_{m}}
$$

Where; $\sigma_{\mathrm{s}}$ and $\sigma_{\mathrm{m}}$ are the standard deviation of satellite and in situ data $\left(\mathrm{cm}^{3} \cdot \mathrm{cm}^{-3}\right)$, respectively and $\mu_{\mathrm{s}}$ is the mean of SMAP soil moisture throughout the whole appraisal time period $\left(\mathrm{cm}^{3} . \mathrm{cm}^{-3}\right)$, and $\mu_{\mathrm{m}}$ is the mean of in situ soil moisture observation $\left(\mathrm{cm}^{3} \cdot \mathrm{cm}^{-3}\right)$. Normalized Difference Vegetation Index (NDVI) is the extensive used vegetation index to recognize healthy vegetation from others or from non-vegetated areas. NDVI was calculated following equation (5):

$$
\mathrm{NDVI}=\left(\frac{N I R-R}{N I R+R}\right)
$$

Where; NIR is Near Infra-Red band(band 5 for both Landsat 8 and ETM+ sensor) and R is Red band (band 4 in case of Landsat 8 and $\mathrm{ETM}^{+}$sensor).

\section{Results}

SMAP data was appraised by comparing with in situ observation with four statistical criteria during 03 April to 03 December 2017 were used to analyze and validation in various land use types. The outcomes of MD, RMSD, ubRMSE and R were computed for SMAP product with in situ observation. As seen in Figure 2, the MD for SMAP soil moisture had positive values of $0.011,0.009,0.023,0.012 \mathrm{~cm}^{3} . \mathrm{cm}^{-3}$ in 08 May, 03 July, 13 September and 03 November respectively, despite in another times, MD had negative values of $0.007 \mathrm{~cm}^{3} . \mathrm{cm}^{-}$ ${ }^{3}$ and $0.021 \mathrm{~cm}^{3} \cdot \mathrm{cm}^{-3}$ in 03 April and 03 December, respectively. The SMAP soil moisture demonstrates good performance with RMSD values ranging from $0.18 \mathrm{~cm}^{3} . \mathrm{cm}^{-3}$ to $0.33 \mathrm{~cm}^{3} . \mathrm{cm}^{-3}$ and ubRMSE value from 0.17 $\mathrm{cm}^{3} . \mathrm{cm}^{-3}$ to $0.33 \mathrm{~cm}^{3} . \mathrm{cm}^{-3}$. Figure 2 demonstrates that, SMAP data compared to the in situ measurement is well correlated, with $\mathrm{r}$ equal 0.77 and $0.72 \mathrm{in} 03$ July and 03 November respectively and great correlated with $r$ equal 0.62 in 03 April respectively also good correlated with $r$ equal $0.56,0.57$ and 0.52 in 08 May, 13 September and 03 December respectively. The SMAP soil moisture demonstrated the good correlation with in situ measurement in 03 July.
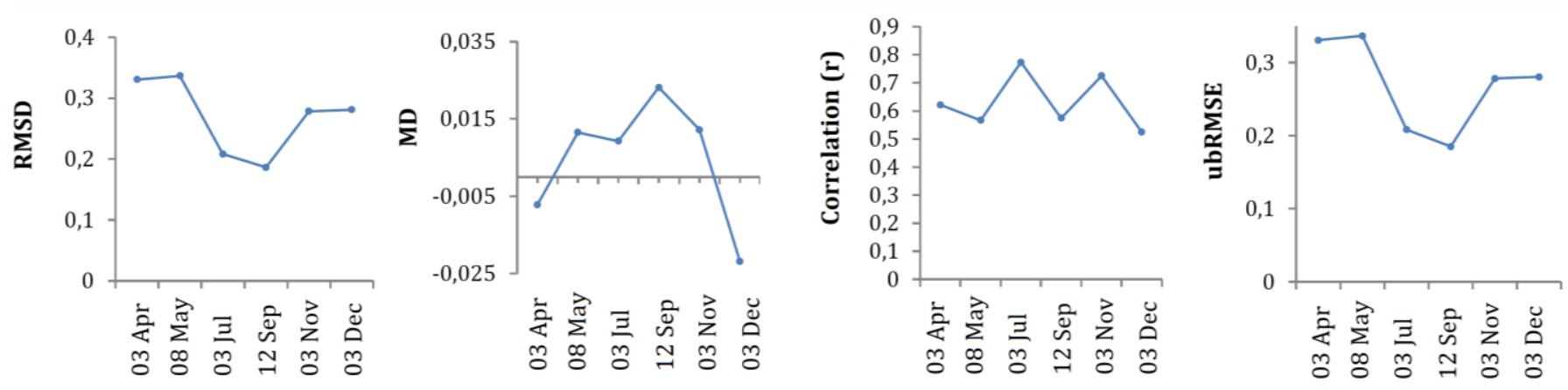

Figure 2. Evolution of four statistics results for SMAP daily data of Simineh-Zarrineh Catchment (Bokan).

As shown in Figure 3, the correlation coefficients for the daily data, as appraised by the different time period, the SMAP data is mostly have great performance. SMAP soil moisture displays distinguish variation. The correlation between SMAP and in situ data were shown in Figure 3. Correlation values between the data sets 
are great along most of the time period in variation of biomes and climate circumstances in 03 July and 03 November with averaged values of $r=0.77$ and $r=0.72$ respectively. In 03 April, 03 September, 08 May and 03 December the correlation between SMAP and in situ data was good with $\mathrm{r}$ values of $0.61,0.57,0.56$ and 0.52 , respectively. So that SMAP soil moisture data had been great performed, as indicated by higher $\mathrm{r}$ values (Figure 2), in the 03 July and November also SMAP soil moisture had the lowest correlation with in situ data in the 03 December relative to the other times.
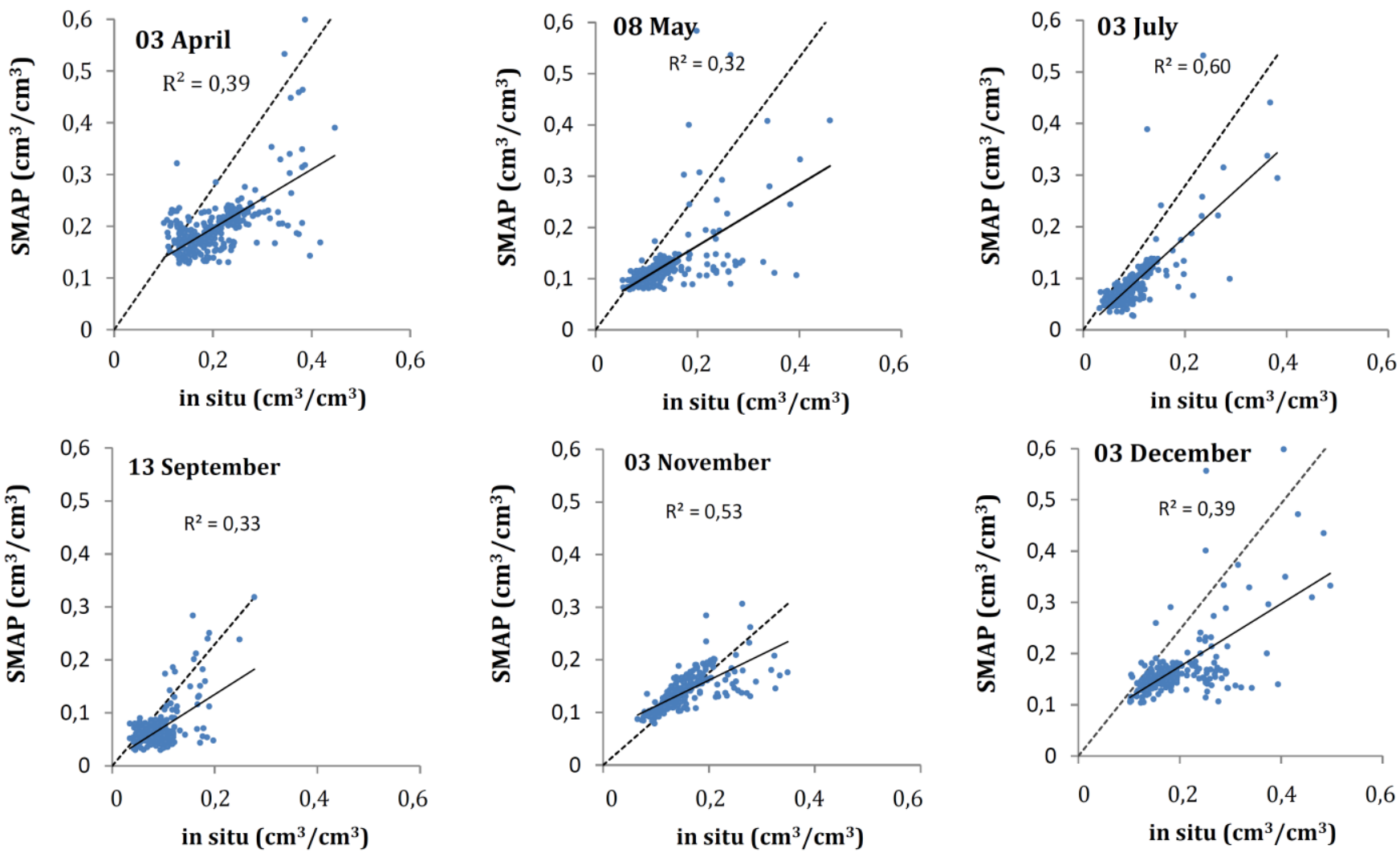

Figure 3. Correlation between SMAP daily data and in situ data in different land use of Simineh-Zarrineh Catchment

(Bokan). 1:1 dot line and fitted solid line.

The accuracy of SMAP data is influenced by the kind of land use. The MD, RMSD, ubRMSE and R were computed for the SMAP data with various land use (Figure 4).

For the SMAP soil moisture data, the good efficiency was achieved in 03 July for the dry lands, where the MD, RMSD and ubRMSE values were $0.08,0.18$ and 0.17 respectively. Low range of soil moisture variation in pasture partially donates to the low RMSD and ubRMSE, as showed in the correlation coefficients (Figure 4). The average value of correlation coefficients for the dry land and irrigated agricultural land were 0.67 and 0.54 ( $p>0.05$ ), respectively. Compared with other land uses, the dry land showed the best $r$ values for SMAP soil moisture data $\left(0.67 \mathrm{~cm}^{3} . \mathrm{cm}^{-3}\right)$.

SMAP soil moisture data obtained in barren land showed negative MD in 03 April and 03 December, a partly high RMSD $\left(0.31 \mathrm{~cm}^{3} \cdot \mathrm{cm}^{-3}\right)$ and a good $\mathrm{r}$ value (0.75) in comparison with in situ data. The minimum MD and the good average value of $r$ outcomes were achieved in dry land for SMAP soil moisture data in 03 July (Figure 4). Daily SMAP data demonstrated the lowest $r$ value for irrigated agricultural land, with an average $r$ value of 0.54 in 03 April to 03 December. The efficiency of the SMAP data retrieved from different land use of Simine-Zarrineh catchment was analyzed. Daily averaged SMAP data were in comparison with in situ data by correlation coefficient (Table 3).

Negative MD values in the 03 April for barren land and irrigated agricultural land and in the 03 December for all land use types had been seen in daily average SMAP soil moisture, which means that the data are underestimates (Figure 4a,f). Low positive MD values in SMAP soil moisture data for whole land use types had been seen in 03 July (Figure 4d). The highest MD values connect to SMAP soil moisture were achieved in the 08 May and for Pasture (Figure 4b). The good results for SMAP soil moisture in the 13 September for dry land obtained in RMSD and ubRMSE (Figure 4c). The SMAP soil moisture showed the lowest RMSD (0.33 
$\left.\mathrm{cm}^{3} \cdot \mathrm{cm}^{-3}\right)$ and ubRMSE $\left(0.32 \mathrm{~cm}^{3} \cdot \mathrm{cm}^{-3}\right)$ in the 03 April and 03 November for irrigated agricultural land (Figure 4a,e). Small MD values occurred in 03 July and 03 November for all land uses, showing that more precise soil moisture predict were achieved for SMAP soil moisture (Figure 4d,e).

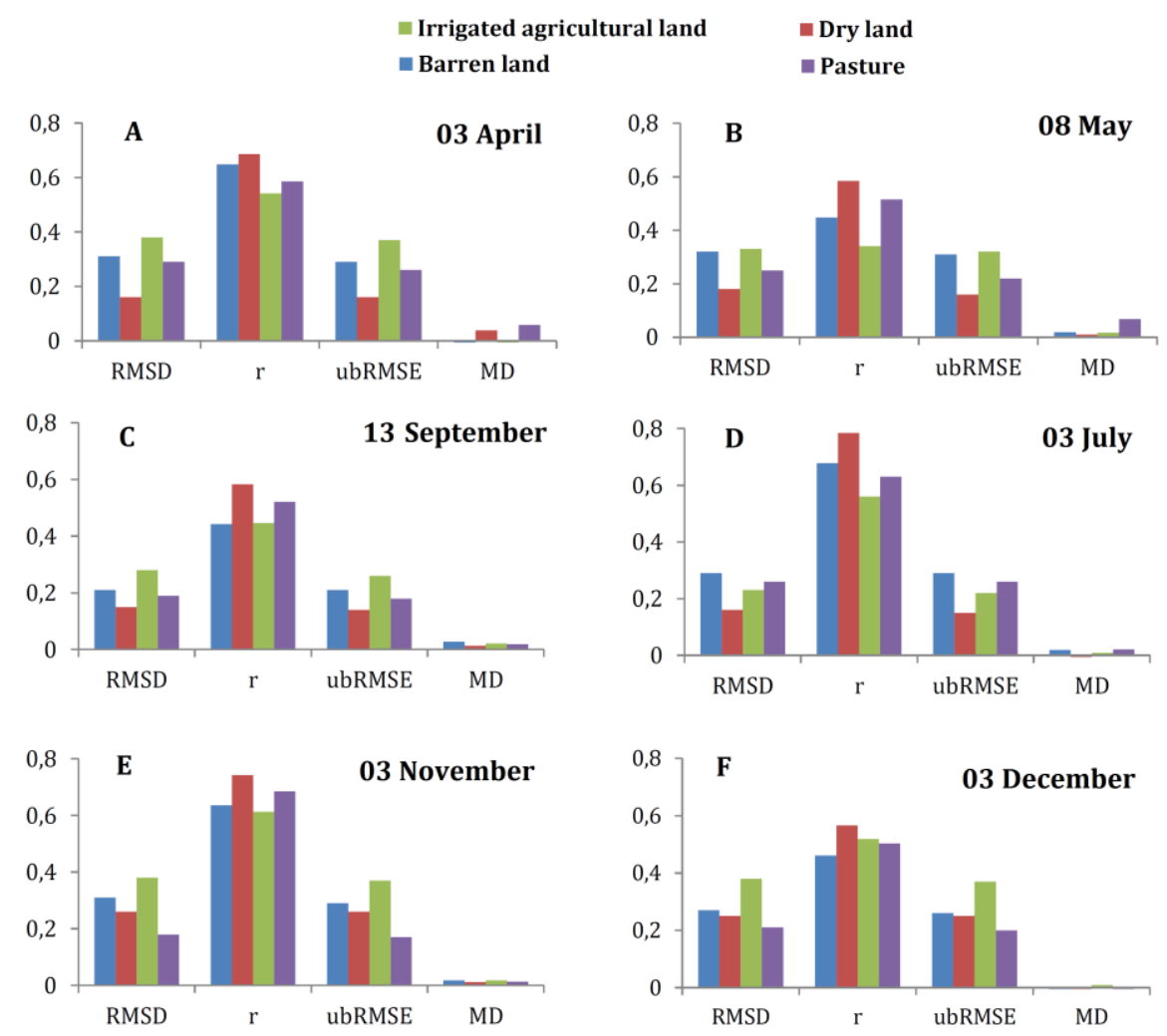

Figure 4. Results of cross validation for SMAP soil moisture daily data with different Land use types of SiminehZarrineh Catchment (Bokan).

Table 3. Mean correlation and standard deviation for SMAP daily data versus in situ data in different land use of SiminehZarrineh Catchment (Bokan).

\begin{tabular}{llllllll}
\hline & Land use type & 03 April & 08 May & 03 July & 13 September & 03 November & 03 December \\
\hline Average & Barren land & 0.64 & 0.57 & 0.75 & 0.55 & 0.71 & 0.67 \\
correlation & Dry land & 0.69 & 0.63 & 0.81 & 0.61 & 0.76 & 0.61 \\
(r) & Irrigated agricultural land & 0.54 & 0.52 & 0.58 & 0.51 & 0.59 & 0.51 \\
& Pasture & 0.59 & 0.47 & 0.66 & 0.57 & 0.63 & 0.59 \\
\hline Standard deviation & Barren land & 0.25 & 0.19 & 0.21 & 0.23 & 0.18 & 0.29 \\
& Dry land & 0.22 & 0.17 & 0.12 & 0.2 & 0.15 & 0.26 \\
& Irrigated agricultural land & 0.26 & 0.23 & 0.27 & 0.29 & 0.25 & 0.33 \\
& Pasture & 0.29 & 0.21 & 0.23 & 0.24 & 0.22 & 0.31 \\
\hline
\end{tabular}

With regard to land uses, dry land, barren land, pasture and irrigated agricultural land the average $\mathrm{r}$ value were $0.76,0.61,0.57$ and 0.54 respectively (Figure 5). The best average R value for dry land, Pasture, Barren land and irrigated agricultural land in this time period were in $03 \mathrm{July}, 03$ November, 03 July and 03 November respectively (Figure 5). SMAP soil moisture had the good results regarding $r$ values $(r>0.70)$ in the 03 July for dry land (Figure 5).

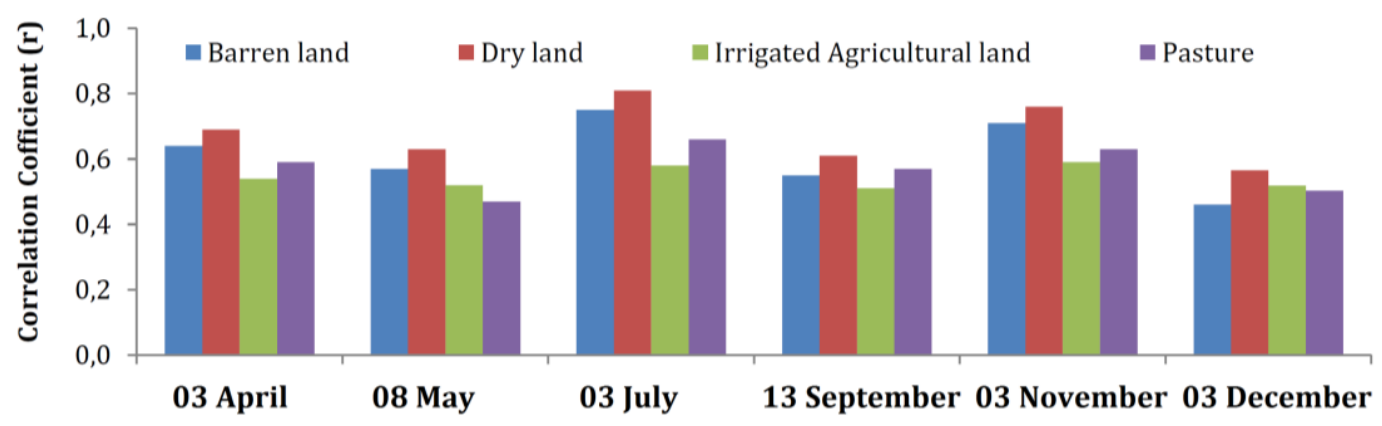

Figure 5: Results of correlation among SMAP data and in situ data for various land use types and different times of Simineh-Zarrineh Catchment (Bokan). 


\section{Discussion}

The vegetation diversity, soil and climate features are the critical parameters that affect the outcomes. Moreover, there is significant spatial variety in various land use types and temporal and dynamical modification in their features, which lead to various grades of efficiency in spatial-temporal assessment. The weak outcomes of this appraisal would be described by some causes. First, uncertainties result from several complicated parameters that influence the radiative transfer model ( $\mathrm{Wu}$ et al., 2016). Second, there exist dissimilarity in the vertical depth checked out by the satellite SMAP soil moisture and the in situ data. The soil water content of the surface layer $(5 \mathrm{~cm})$ detected by SMAP soil moisture will be different from the deeper layer which observed by the soil sampling $(5 \mathrm{~cm})$. The soil water content in the surface layer that detected by satellite tends to react further quickly to atmospheric process than the deeper soil layer.

The SMAP protocol utilize an Ensemble Kalman Filter (EnKF) to be revealed SMAP data with soil moisture prediction from the NASA Catchment land surface model (Reichle et al.,2016). Various recovery procedure and brightness temperature measurement was utilized by SMAP (Das et al., 2016; Das et al., 2011), which contributes to the differences evaluation results. The immense nonuniformity in each pixel comparative to the in situ observation negatively affected the accuracy of the appraisal (Jackson et al., 2010). The parameters discussed above may also use to the SMAP soil moisture. The SMAP soil moisture ordinary demonstrated well concurrence with the reference data and successfully captured the spatial and temporal changes showed in Figures 2-5 and Tables 3. As an example, SMAP soil moisture performed good in the areas covered by dry land, because of low fluctuation of vegetation in this time period (Dorigo et al., 2010). The apposite, SMAP soil moisture showed poor correlations among the reference data in irrigated agricultural land (Figures 4 and 5), since that fluctuation of vegetation in its area is very high. These impacts would be originated to the high range of changes in soil moisture in these areas, which approximately fit to the anticipated retrieval accuracy of the satellite data (Al-Yaari et al., 2014). Meanwhile SMAP soil moisture also showed low correlations with the in situ data in Pasture areas in 08 May. As shown in Figure 1, about 35.65 percentage of this study area covered with its.

The outcomes approved that vegetation performs a great role in the appraisal efficiency of the SMAP product. It could be seen from Figure 6 the NDVI were large through the year for Irrigated agricultural land. The correlation among the SMAP soil moisture calculated $\mathrm{r}$ with in situ and NDVI is relative numerous with a high value of 0.53 (Figure 7), which revealed the effect of vegetation to soil moisture data. The quality of remotely sensed data reduces with increasing vegetation severity in dry land, Pasture and Irrigated agricultural land (Figure 7). These results were accordant with former researches (Brocca et al., 2013a,b,c). While Barren land areas did not exhibit same correlation structure with other land use types, this can be partially described by the very low vegetation in Barren land (Figure 7).

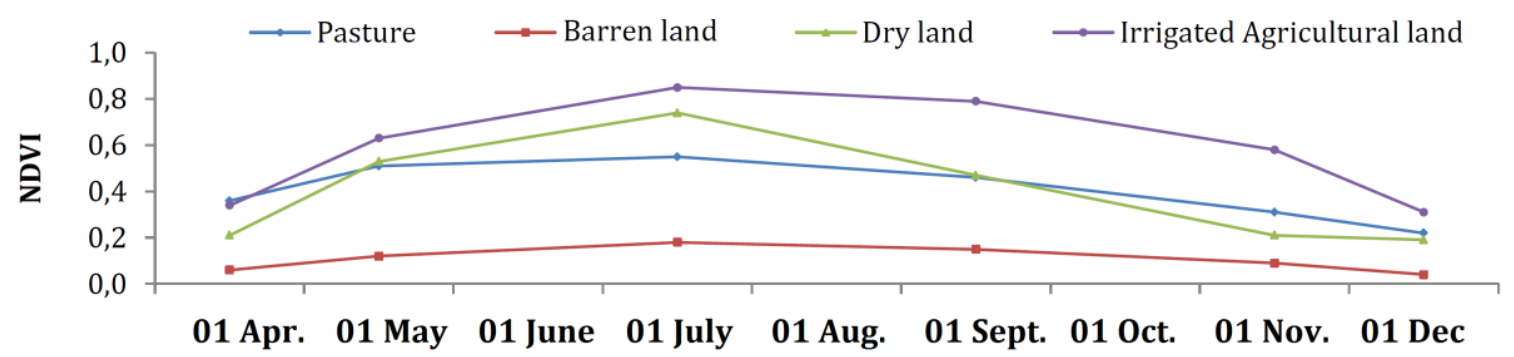

Figure 6. The temporal variation of mean NDVI for various land uses.

Investigating the temporal trends further nearly, SMAP soil moisture oriented to underestimate soil moisture in 03 April and 03 December and presents properly throughout the dry season (e.g., from 08 May to 03 September) than throughout the rest of the year. The causes can be linked to some aspects. First of all, low frequency of precipitation in summer than other time periods, that partially showed the good performance of SMAP data in summer. Meantime, the April to September in addition has plentiful vegetation, which more intensifies the incompatibility with in situ soil moisture. In this research, with NDVI of various land use types from April to December 2017 (Figures 6) and the correlation among SAMP soil moisture appraised r versus in situ and NDVI (Figure 7), impact of vegetation for soil moisture data can be measurable described. 


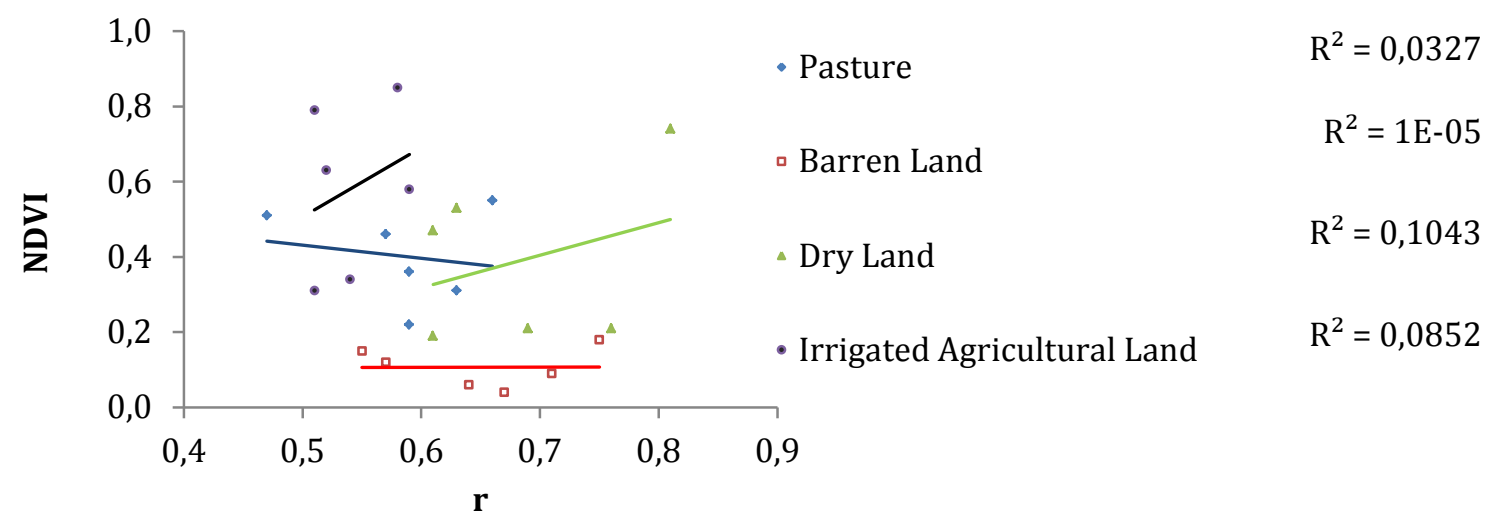

Figure 7. Correlation coefficient (r) between NDVI and SMAP soil moisture evaluation results with in situ (r).

Moreover, several aspects of the spatiotemporal data would be underlined. From Figure 4, it would be understand that the dry land outperforms the other land use throughout almost the whole time period. As exhibit from Figure 7, bigger NDVI in irrigated agricultural land donated to the poor performance. In spite the fact that in dry land the NDVI exhibit great effect on the appraisal of SMAP soil moisture data, in other words several parameters as an example large spatial intricacy of topography and surface characteristic may principally affect the appraisal outcomes. Nevertheless, the SMAP soil moisture show reverse outcomes for correlation from 03 April and 03 December in barren land as shown in Figure 4. This outcome would be because of a number of parameters, comprising greater vegetation coverage or variation in precipitation. Regarding the complete divergence among satellite and in situ soil moisture data, SMAP soil moisture exhibited relatively low mean RMSD and ubRMSE (Figure 2). In Figure 4, the dry land and pasture shows lower RMSD for the SMAP data. Meanwhile, the dry land exhibits relatively smaller RMSD and ubRMSE over the time period. It is mostly shown from Figure 4 that the dry land is principally situated in area with low NDVI variation over the year (Figure 6). The small range and change of soil moisture in these land uses partially donated to the small RMSD and ubRMSE. For validation of remotely sensed data, the greatest interesting subject is the representativeness of the in situ observations; both in situ sensor errors and the taken sampling of the true field mean soil moisture on the basis of a finite number of point samples can reason bias and magnitude errors in the predictions (Entekhabi et al., 2014). Despite the fact that SMAP data exhibit well concurrence with in situ data in $r$, for instance, dry land executed good with daily mean measurements for SMAP data, moderate executes were found for irrigated agricultural land for SMAP data, however the ubRMSE value of SMAP data in different land use and time periods can't meet the design criteria. Anyway, systematic deviations among remotely sensed and in situ data are frequently discovered although the temporal dynamics are highly similar (Loew and Schlenz, 2011). In this research, in situ data near water body were eliminated. Therefore, differences may seem somewhat. It has been conclude that SMAP soil moisture products over Simineh- Zarrineh catchment (Bokan) are practical for different utilization such as predicting rainfall, monitoring of climate change and hydrological modeling, that based on good remarked universal soil moisture datasets from remotely sensed.

\section{Conclusion}

This research prepared an inclusive assessment of the SMAP data across the Simineh- Zarrineh catchment (Bokan) using in situ data of 287 sampling point distributed through this catchment as ground control. The results indicate the SMAP soil moisture data appear relatively good agreement with in situ data placed in various land uses and arranged in a time periods. This conclusion can be supported well by the four statistical criteria (MD, RMSD, ubRMSE and R). Our analysis evaluation mentions that the efficiency of the SMAP soil moisture changes rely on their spatial distribution, time periods distribution and land use types. Regarding that spatial series analysis, SMAP data in the land use covered by dry land exhibit well concurrence with in situ data. Poor correlation coefficient in 03 December and a good correlation coefficient in 03 July have been shown. Generally results demonstrate best performances of the product to retrieve surface soil moisture as well as short term variability. Correlation values among the data sets are very satisfactory across most of the inspected sites situated in contrasted various land use types with mean values of $0.68,0.64,0.58$ and 0.54 for dry land, barren land, pasture and irrigated agricultural land respectively. It is important to express that although the appraised SMAP soil moisture products utilized in this research were discovered to be very dependable in accord with the spatial and temporal analysis. Concentrated on the effect of spatial-temporal characteristics, the land use types with pasture, irrigated 
agricultural land, barren land and dry land were significantly influenced by seasonal variation. Generally, the conducted validation assessment permitted definition of the dependability of SMAP data through a strong and standardized compared by ground measurements for assessment of spatiotemporal series on daily time scales across the Simineh- Zarrineh catchment (Bokan). In summary, the accuracy and reliability of the SMAP data predicts changes rely on land uses. These outcomes are in concurrence with our anticipation that SMAP data are mostly of best quality over low vegetation covered regions. This subject would be addressed in future researches to enhance the accuracy of SMAP data predicts.

\section{Acknowledgements}

The authors appreciate to Por Bare Baghestan Company for conducted to analyze the soil samples. We are very much thankful to Dr. Luca Brocca from IRPI for their valuable guidance.

\section{References}

Ahmadaali, J., Barani, GH.A., Qaderi, K., Hessari, B., 2018. Analysis of the effects of water management strategies and climate change on the environmental and agricultural sustainability of Urmia Lake Basin, Iran. Water 10(2): 160.

Albergel, C., de Rosnay, P., Gruhier, C., Munoz-Sabater, J., Hasenauer, S., Isaksen, L., Kerr, Y., Wagner, W., 2012. Evaluation of remotely sensed and modeled soil moisture products using global ground-based in situ observations. Remote Sensing of Environment 118: 215-226.

Al-Yaari, A., Wigneron, J.P., Ducharne, A., Kerr, Y., de Rosnay, P., de Jeu, R., Govind, A., Al Bitar, A., Albergel, C., MuñozSabater, J., 2014. Global-scale evaluation of two satellite-based passive microwave soil moisture datasets (SMOS and AMSR-E) with respect to land data assimilation system estimates. Remote Sensing of Environment 149: 181195.

Al-Yaari, A., Wigneron, J.P., Kerr, Y., de Jeu, R., Rodriguez-Fernandez, N., van der Schalie, R., Al Bitar, A., Mialon, A., Richaume, P., Dolman, A., 2016. Testing regression equations to derive long-term global soil moisture datasets from passive microwave observations. Remote Sensing of Environment 180: 453-464.

Barichivich, J., Briffa, K.R., Myneni, R., van der Schrier, G., Dorigo, W., Tucker, C.J.,Osborn, T.J., Melvin, T.M., 2014. Temperature and snow-mediated moisture controls of summer photosynthetic activity in northern terrestrial ecosystems between 1982 and 2011. Remote Sensing 6(2): 1390-1431.

Brocca, L., Melone, F., Moramarco, T., Wagner, W., Naeimi, V., Bartalis, Z., Hasenauer, S., 2010. Improving runoff prediction through the assimilation ofthe ASCAT soil moisture product. Hydrology and Earth System Sciences 14(10): 1881-1893.

Brocca, L., Hasenauer, S., Lacava, T., Melone, F., Moramarco, T., Wagner, W., Dorigo, W., Matgen, P., Martinez-Fernandez, J., Llorens, P., Latron, J., Martin, C., Bittelli, M., 2011. Soil moisture estimation through ASCAT and AMSR-E sensors: An intercomparison and validation study across Europe. Remote Sensing of Environment 115(12): 33903408.

Brocca, L., Ponziani, F., Moramarco, T., Melone, F., Berni, N., Wagner, W., 2012. Improving landslide forecasting using ASCAT-derived soil moisture data: A case study of the Torgiovannetto Landslide in Central Italy. Remote Sensing 4(5): 1232-1244.

Brocca, L., Melone, F., Moramarco, T., Wagner, W., Albergel, C., 2013a. Scaling and filtering approaches for the use of satellite soil moisture observations. In: Remote Sensing of Energy Fluxes and Soil Moisture Content. Petropoulos, G.P. (Ed.). CRC Press, Taylor and Francis Group, Boca Raton, New York, USA. pp. 411-426.

Brocca, L., Moramarco, T., Melone, F., Wagner, W., 2013b. A new method for rainfall estimation through soil moisture observations. Geophysical Research Letters 40(5): 853-858.

Brocca, L., Tarpanelli, A., Moramarco, T., Melone, F., Ratto, S.M., Cauduro, M., Ferraris, S., Berni, N., Ponziani, F., Wagner, W., Melzer, T., 2013c. Soil moisture estimation in alpine catchments through modeling and satellite observations. Vadose Zone Journal 12(3): vzj2012.0102

Chen, F., Crow, W.T., Holmes, T.R.H., 2012. Improving long-term, retrospective precipitation datasets using satellitebased surface soil moisture retrievals and the soil moisture analysis rainfall tool. Journal of Applied Remote Sensing 6(1): 063604

Crow, W.T., Berg, A.A., Cosh, M.H., Loew, A., Mohanty, B.P., Panciera, R., de Rosnay, P., Ryu, D., Walker, J.P., 2012. Upscaling sparse ground-based soil moisture observations for the validation of coarse-resolution satellite soil moisture products. Reviews of Geophysics 50(2): RG2002.

Das, N.N., Entekhabi, D., Dunbar, R.S., Njoku, E.G., Yueh, S.H., 2016. Uncertainty estimates in the SMAP combined activepassive downscaled brightness temperature. IEEE Transactions on Geoscience and Remote Sensing 54(2): 640650.

Das, N.N., Entekhabi, D., Njoku, E.G., 2011. An algorithm for merging SMAP radiometer and radar data for highresolution soil-moisture retrieval. IEEE Transactions on Geoscience and Remote Sensing 49(5): 1504-1512.

Dorigo, W.A., Scipal, K., Parinussa, R.M., Liu, Y.Y., Wagner, W., de Jeu, R.A.M., Naeimi, V., 2010. Error characterisation of global active and passive microwave soil moisture datasets. Hydrology and Earth System Sciences 14(12): 26052616. 
Dorigo,W.A., Gruber, A., de Jeu, R.A.M., Wagner, W., Stacke, T., Loew, A., Albergel, C., Brocca, L., Chung, D., Parinussa, R.M., Kidd, R., 2015. Evaluation of the ESA CCI soil moisture product using ground-based observations. Remote Sensing of Environment 162: 380-395.

Entekhabi, D., Njoku, E.G., O’Neill, P.E., Kellogg, K.H., Crow, W.T., Edelstein, W.N., Entin, J.K., Goodman, S.D., Jackson, T.J., Johnson, J., 2010. The Soil Moisture Active Passive (SMAP) mission. Proceedings of the IEEE 98(5): 704-716.

Entekhabi, D., Yueh, S., O’Neill, P.E., Kellogg, K.H., Allen, A., Bindlish, R., Brown, M., Chan, S., Colliander, A., Crow, W.T., Das, N., De Lannoy, G., Dunbar, R.S., Edelstein, W.N., Entin, J.K., Escobar, V., Goodman, S.D., Jackson, T.J., Jai, B., Johnson, J., Kim, E., Kim, S., Kimball, J., Koster, R.D., Leon, A., McDonald, K.C., Moghaddam, M., Mohammed, P., Moran, S., Njoku, E.G., Piepmeier, J.R., Reichle, R., Rogez, F., Shi, J.C., Spencer, M.W., Thurman, S.W., Tsang, L., Van Zyl, J., Weiss, B., West, R., 2014. SMAP Handbook-Soil Moisture Active Passive: Mapping Soil Moisture and Freeze/Thaw from Space. Jet Propulsion Laboratory (JPL) Publication. Pasadena, CA.

Jackson, T.J., Cosh, M.H., Bindlish, R., Starks, P.J., Bosch, D.D., Seyfried, M., Goodrich, D.C., Moran, M.S., Du, J.Y., 2010, Validation of advanced microwave scanning radiometer soil moisture products. IEEE Transactions on Geoscience and Remote Sensing 48(12): 4256-4272.

Kerr, Y., Waldteufel, P., Wigneron, J.P., Delwart, S., Cabot, F., Boutin, J., Escorihuela, M.J., Font, J., Reul, N., Gruhier, C., Juglea, S.E., Drinkwater, M.R., Hahne, A.,Martin-Neira, M., Mecklenburg, S., 2010. The SMOS mission: new tool formonitoring key elements of the global water cycle. Proceedings of the IEEE 98(5): 666-687.

Kerr, Y.H., Waldteufel, P., Richaume, P., Wigneron, J.P., Ferrazzoli, P., Mahmoodi, A., Al Bitar, A., Cabot, F., Gruhier, C., Juglea, S.E., Leroux, D., Mialon, A., Delwart, S., 2012. The SMOS soil moisture retrieval algorithm. IEEE Transactions on Geoscience and Remote Sensing 50(5): 1384-1403.

Leroux, D.J., Kerr, Y.H., Al Bitar, A., Bindlish, R., Jackson, T.J., Berthelot, B., Portet, G., 2014. Comparison between SMOS, VUA, ASCAT, and ECMWF soil moisture products over four watersheds in US. IEEE Transactions on Geoscience and Remote Sensing 52(3): 1562-1571.

Loew, A., Schlenz, F., 2011. A dynamic approach for evaluating coarse scale satellite soil moisture products. Hydrology and Earth System Sciences 15(1): 75-90.

Miralles, D.G., van den Berg, M.J., Teuling, A.J., de Jeu, R.A.M., 2012. Soil moisture-temperature coupling: A multiscale observational analysis. Geophysical Research Letters 39(21): L21707.

Owe, M., de Jeu, R., Van de Griend, A., 2001. Estimating long term surface soil moisture from satellite microwave observations in Illinois, USA. Remote Sensing and Hydrology 2000 (Proceedings of a symposium held at Santa Fe, New Mexico, USA, April 2000). IAHS Publication No. 267, 2001.

Parinussa, R., Meesters, A.G.C.A., Liu, Y.Y., Dorigo, W.; Wagner, W.; de Jeu, R.A.M., 2011 An analytical solution to estimate the error structure of a global soil moisture data set. IEEE Geoscience and Remote Sensing Letters 8(4): 779-783.

Parinussa, R.M., Holmes, T.R.H., Wanders, N., Dorigo,W.A., de Jeu, R.A.M., 2015. A preliminary study toward consistent soil moisture from AMSR2. Journal of Hydrometeorology 16: 932-947.

Reichle, R., Koster, R., De Lannoy, G., Crow, W., Kimball, J., 2016. Level 4 Surface and Root Zone Soil Moisture (L4_SM) Data Product. Available at [Access date: 03.10.2018]: https://nsidc.org/sites/nsidc.org/files/technicalreferences/272_L4_SM_RevA_web.pdf

Sanchez, N., González-Zamora, Á., Martínez-Fernández, J., Piles, M., Pablos, M., 2018. Integrated remote sensing approach to global agricultural drought Monitoring. Agricultural and Forest Meteorology 259: 141-153.

Seneviratne, S.I., Corti, T., Davin, E.L., Hirschi, M., Jaeger, E.B., Lehner, I., Orlowsky,B., Teuling, A.J., 2010. Investigating soil moisture-climate interactions in a changing climate: a review. Earth-Science Reviews 99(3-4): 125-161.

Taylor, C.M., de Jeu, R.A.M., Guichard, F., Harris, P.P., Dorigo, W.A., 2012. Afternoon rain more likely over drier soils. Nature 489: 423-426.

Urmia Lake Restoration National Committee. 2015. Necessity of Lake Urmia Resuscitation, Causes of Drought and Threats; Report No: ULRP-6-4-3-Rep 1; Urmia Lake Restoration National Committee: Tehran, Iran.

Wang, S., Mo, X., Liu, S., Lin, Z., Hu, S., 2016. Validation and trend analysis of ECV soil moisture data on cropland in North China plain during 1981-2010. International Journal of Applied Earth Observation and Geoinformation 48: 110121.

Wilson, D. J., Western, A. W., Grayson, R.B., 2004. Identifying and quantifying sources of variability in temporal and spatial soil moisture observations. Water Resources Research 40(2): W02507.

Wu, Q.S., Liu, H.X., Wang, L., Deng, C.B., 2016. Evaluation of AMSR2 soil moisture products over the contiguous united states using in situ data from the international soil moisture network. International Journal of Applied Earth Observation and Geoinformation 45: 187-199.

Zeng, J.Y., Chen, K.S., Bi, H.Y., Chen, Q., 2016. A preliminary evaluation of the SMAP radiometer soil moisture product over United States and Europe using ground-based measurements. IEEE Transactions on Geoscience and Remote Sensing 54(8): 4929-4940. 